\title{
Physical and Chemical Properties of Kapok (Ceiba pentandra) and Balsa (Ochroma pyramidale) Fibers ${ }^{1}$
}

\author{
Renny Purnawati ${ }^{2} \cdot$ Fauzi Febrianto $\mathbb{D}^{2, \dagger} \cdot$ I Nyoman $\mathrm{J}$ Wistara $^{2} \cdot$ Siti Nikmatin $^{3}$ • \\ Wahyu Hidayat ${ }^{4} \cdot$ Seung Hwan Lee ${ }^{5} \cdot$ Nam Hun Kim $^{5, \dagger}$
}

\begin{abstract}
Natural fibers derived from lignocellulosic materials are considered to be more environment-friendly than petroleum-based synthetic fibers. Several natural fibers, such as seedpod fibers, have a potential for development, including kapok and balsa fibers. The characteristics of both fibers were evaluated to determine their suitability for specific valuable applications. The purpose of this study was to analyze some important fundamental properties of kapok and balsa fibers, including their dimensions, morphology, chemical components, and wettability. The results showed that the average fiber lengths for kapok and balsa were 1.63 and $1.30 \mathrm{~cm}$, respectively. Kapok and balsa fibers had thin cell walls and large lumens filled with air. The kapok fiber was composed of 38.09\% $\alpha$-cellulose, $14.09 \%$ lignin, and $2.34 \%$ wax content, whereas the balsa fiber was composed $44.62 \% \alpha$-cellulose, $16.60 \%$ lignin, and $2.29 \%$ wax content. The characteristics of kapok and balsa fibers were examined by X-ray diffraction, Fourier-transform infrared spectroscopy and differential scanning calorimetry analyses. The contact angle of the distilled water on kapok and balsa fibers was more than $90^{\circ}$, indicating that both fibers are hydrophobic with low wettability properties because of to the presence of wax on the fiber surface.
\end{abstract}

Keywords: balsa fiber, chemical compounds, fiber dimension, kapok fiber, morphology, relative crystallinity, wettability

\section{INTRODUCTION}

Indonesia has a large amount of natural lignocellulosic fibers with potential use in a variety of industrial products based on available technology.
Despite some technological advancement, specific characteristics of the materials have become an important factor in developing new fiber-based products. Several natural fibers with the potential to be developed are fibers from the fruit of kapok (Ceiba

\footnotetext{
1 Date Received May 17, 2018, Date Accepted July 9, 2018

2 Department of Forest Products, Faculty of Forestry, Bogor Agricultural University, Indonesia

${ }^{3}$ Department of Physics, Faculty of Mathematics and Natural Science, Bogor Agricultural University, Indonesia

${ }^{4}$ Department of Forestry, Faculty of Agriculture, Lampung University, Indonesia

${ }^{5}$ Department of Forest Biomaterials Engineering, College of Forest and Environmental Science, Kangwon National University, Republic of Korea

$\dagger$ Corresponding author: Fauzi Febrianto (e-mail: febrianto76@yahoo.com, ORCID: 0000-0002-0964-2179)

† Corresponding author: Nam Hun Kim (e-mail: kimnh@kangwon.ac.kr, ORCID: 0000-0002-4416-0554)
} 
Renny Purnawati · Fauzi Febrianto - I Nyoman J Wistara - Siti Nikmatin - Wahyu Hidayat •

Seung Hwan Lee $\cdot$ Nam Hun Kim

pentandra) and balsa (Ochroma pyramidale); however, these fibers, especially balsa fibers, have not been thoroughly studied until now.

Indonesia is one of the world's biggest kapok exporters. Around 52,800 tons of kapok were produced from 143.7 ha of community plantations in Java (BPS, 2015). Meanwhile, balsa wood is one of the fast-growing species in Indonesian plantation forests, and the fibers from its fruits could add to the product value.

Balsa and kapok fibers have similar physical properties. Kapok trees are widely distributed in tropical areas. They are 60-70 $\mathrm{m}$ tall, their trunks expand to $3 \mathrm{~m}$ in diameter, and they have palm-shaped leaves. An adult kapok tree produces hundreds of seedpods with black seeds and yellow fibers. The extracted fibers are smooth and light; they are used in manufacturing pillows, life preservers, sleeping bags, and insulation. Moreover, kapok has also been investigated as an absorbent material for oil and acoustic insulation (Likon et al., 2013; Wang et al., 2012; Rengasamy et al., 2011; Veerakumar and Selvakumar, 2010).

Balsa trees are fast-growing evergreen trees that can reach up to $30 \mathrm{~m}$ in height and $1.8 \mathrm{~m}$ in diameter at breast height. They typically have buttress roots. They have a reputation as the lightest commercial wood for various purposes. The silky fibers of its fruit can be used as a material for pillows, mattresses, and cushions. Nevertheless, there are no detailed studies previously reported on the basic properties of balsa fiber.

Kapok and balsa fibers as natural resources can potentially be developed for several applications (Purnawati et al., 2018). However, the characteristics of kapok and balsa fibers must be identified in order to determine their suitability for various applications and products. The purpose of this study was to analyze some important properties of kapok and balsa fibers, including their morphology, chemical composition, relative crystallinity, thermal properties, and wettability.

\section{MATERIALS and METHODS}

\subsection{Materials}

Kapok and balsa seedpods were obtained from the plant collection of Bogor Agricultural University, Dramaga, West Java (Fig. 1).
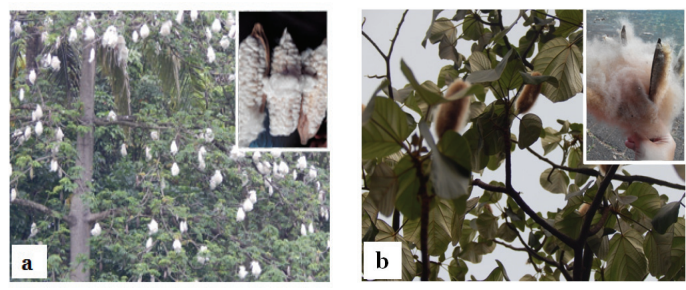

Fig. 1. Trees of kapok (a) and balsa (b) with their seedpods.

Kapok and balsa fibers were removed from their pods, separated from their seeds, and dried at room temperature $\left(25^{\circ} \mathrm{C}\right)$. The fibers were then ground to 40-60 mesh size for the purpose of chemical component analysis.

\subsection{Methods}

\subsubsection{Microscopy}

Kapok and balsa fibers were successively rinsed with $10 \%, 30 \%$, and $50 \%$ aqueous ethanol. Then, the fibers were stained with $1 \%$ safranine solution for $24 \mathrm{~h}$. Finally, they were rinsed with $50 \%$ ethanol to remove the excess dye. Fiber morphology was observed by digital photomicroscopy (Carton CB-10, Thailand) using a 5 MP USB eyepiece camera. Fiber dimensions (length, diameter, and cell wall thickness) were analyzed by FIJI ImageJ 1.51p software for Windows.

Fiber morphology was also analyzed using scanning electron microscopy (SEM; JEOL-JSM-6510) at an accelerating voltage of $10 \mathrm{kV}$. Samples were placed on a carbon tape attached to a 1-cm-diameter holder and coated with osmium. 


\subsubsection{X-ray diffraction analysis}

The relative crystallinity index (CrI) of the materials was tested using an X-ray diffractometer (XRD, Shimadzu XRD-7000 MaximaX series). A Ni-filtered $\mathrm{CuK} \alpha$ X-ray operating at $40 \mathrm{kV}$ and $30 \mathrm{~mA}$ was used to analyze the cellulose crystalline properties for both fibers. Relative crystallinity was calculated by the following formula (Segal et al., 1959):

$$
\operatorname{CrI}=\left[\left(\mathrm{I}_{200}-\mathrm{I}_{\mathrm{am}} / \mathrm{I}_{200}\right)\right] \times 100, \cdots
$$

where $I_{200}$ is the maximum intensity of the lattice diffraction of cellulose type $I$ and $I_{a m}$ is the intensity diffraction of the amorphous cellulose.

The size of the crystals ( $\mathrm{T}$ ) was calculated using the Scherrer equation (Smilgies, 2009) as follows:

$$
T=\frac{K \lambda}{\beta \cos \theta}
$$

where $\mathrm{T}$ is the mean size of the ordered (crystalline) domains, $K$ is the shape factor (approximately 0.9), $\lambda$ is the $\mathrm{X}$-ray wavelength, $\beta$ is the line full-width at half-maximal intensity, and $\theta$ is the Bragg angle.

\subsubsection{Wettability}

The sessile-drop method was chosen for contact angle measurement, and the dynamic contact angle was determined using a Phoenix 300 Contact Angle Analyzer (Surface Electro Optics, Korea) (Suryadi, 2017). Demineralized water and methanol were used as the polar liquids, and hexane was used as the non-polar liquid. The three-probe liquids were placed on the surface of the fiber. Each droplet was $5 \mu \mathrm{L}$ in volume, and a total of three droplets were analyzed for each liquid. The contact angle measurement was performed by capturing a droplet image using Surfaceware 8 software and a camera-based contact angle analysis system. The process of capturing the image was continuously conducted at the beginning of the test, after $5 \mathrm{~min}$, and after $10 \mathrm{~min}$. The angles were measured on both sides of the droplet. All tests were carried out at room temperature $\left(25^{\circ} \mathrm{C}\right)$.

\subsubsection{Differential scanning calorimetry analysis}

Kapok and balsa fibers were tested by differential scanning calorimetry (DSC) to measure the thermal transition of the fibers. A fiber sample of approximately $10 \mathrm{mg}$ was placed in a small aluminum crucible and subjected to a temperature program; Shimadzu DSC-60 was operated in a dynamic mode in the temperature range of $30{ }^{\circ} \mathrm{C}$ to $500{ }^{\circ} \mathrm{C}$ and a heating rate of 10 ${ }^{\circ} \mathrm{C} / \mathrm{min}$ in a nitrogen environment purged at $25 \mathrm{~mL} / \mathrm{min}$.

\subsubsection{Chemical analysis}

The chemical compositions, including extractives, ash, and lignin content, of kapok and balsa fibers were determined in accordance with the TAPPI standards (TAPPI T204 om-88, 1988; TAPPI T211 om-02, 2002; and TAPPI T222 om-88, 1988). The holocellulose ( $\alpha$ -cellulose + hemicellulose) content was estimated by the acid chloride method, and the $\alpha$-cellulose content was determined by treating the holocellulose with a sodium hydroxide solution (Browning, 1967). Wax content was determined in accordance with the AATCC Test Method 97 (American Association of Textile Chemists and Colorists, 2012).

The functional groups in kapok and balsa fibers were determined using Fourier-transform infrared (FTIR) spectroscopy (MB3000 ABB). Approximately 2 mg of fiber was mashed, mixed with $200 \mathrm{mg} \mathrm{KBr}$, and then pressed into 1-mm-thick disks. The spectra were recorded in the range of $4000-450 \mathrm{~cm}^{-1}$.

\section{RESULTS and DISCUSSION}

\subsection{Fiber morphology}

Examination by SEM showed that kapok and balsa 
Renny Purnawati · Fauzi Febrianto - I Nyoman J Wistara - Siti Nikmatin - Wahyu Hidayat • Seung Hwan Lee $\cdot$ Nam Hun Kim

fibers had a hollow structure with a thin fiber wall and a large lumen filled with air (Fig. $2 b$ and Fig. 2d). Single-cell seed fibers such as kapok, balsa, and cotton are different from other natural fibers such as wood, hemp, jute etc. Unicellular cellulosic fibers are typically oval- or cylindrical, are long with pointed ends, and have thin cell walls with large lumens, which led to low fiber densities for both kapok and balsa.

Meiwu et al. (2010) and Mwaikambo (2006) stated that kapok was the lightest fiber in the world. The apparent specific gravity of the Indian kapok fiber was approximately 0.0554 , whereas that of Japanese kapok was approximately 0.0388 . Moreover, kapok fiber was six times lighter than cotton (Mwaikambo, 2006). Meanwhile, cotton fiber had a density of $0.29 \mathrm{~g} / \mathrm{cm} 3$ according to a study conducted by Meiwu et al. (2010).

Balsa fiber had a light brown color, whereas kapok had a yellowish white color. Both fibers were luminous because of the wax content of the fiber surface, showing similarity to the silk fibers. Both fibers were about two times longer than non-timber lignocellulosic fibers, such as pineapple, corn, coconut, bagasse, banana, hay, and sorghum (Reddy and Yang, 2005). However, the kapok and balsa fiber lengths were shorter than those of cotton, hemp, and flax (Mwaikambo, 2006).

Parameters such as fiber length, diameter, and cell wall thickness of kapok and balsa are shown in Table 1. The length of the kapok fiber ranged from 13.79 to $18.84 \mathrm{~mm}$, whereas that of balsa ranged from 10.36 to $15.70 \mathrm{~mm}$. Kapok fibers were longer than balsa fibers, but their diameter and cell wall thickness were less than those of balsa fibers. Kapok fibers had an exceptional liquid-retention capability considering their large lumens. Their excellent thermal and acoustic insulating properties, high buoyancy, and good absorbency for oil and other non-polar liquids distinguish kapok from most other cellulosic fibers (Wang et al., 2012; Lim and Huang, 2007; Zheng et al., 2015). Balsa fibers may have similar properties because of their similar morphology.
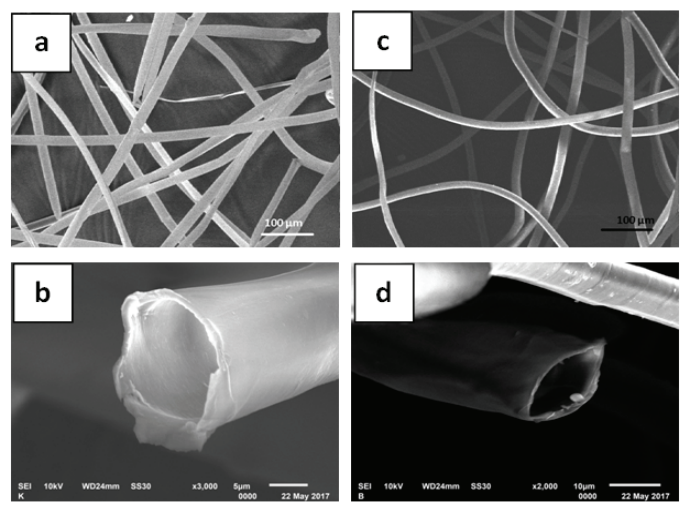

Fig. 2. SEM images of the kapok fiber (a and b) and balsa fiber (c and d).

Table 1. Dimensions of kapok and balsa fibers

\begin{tabular}{lcc}
\hline Dimension & Kapok & Balsa \\
\hline \hline Length $(\mathrm{mm})$ & $16.32 \pm 2.54$ & $13.01 \pm 2.69$ \\
Width $(\mu \mathrm{m})$ & $17.59 \pm 3.72$ & $19.25 \pm 2.69$ \\
$\begin{array}{l}\text { Cell wall thickness } \\
(\mu \mathrm{m})\end{array}$ & $1.34 \pm 0.77$ & $2.40 \pm 0.97$ \\
\hline
\end{tabular}

\subsection{X-ray diffraction analysis}

Fig. 3 shows X-ray diffractograms that display peaks of $2 \theta=22.15^{\circ}$ in kapok fibers and $22.31^{\circ}$ in balsa fibers, which are characteristic of cellulose type I crystals. The crystallinity index (CrI) of the kapok fiber was $35.65 \%$, and that of balsa fiber was $31.40 \%$. According to Poletto et al. (2014), the CrI for both fiber types was similar to the values for jute (34.3\%), kenaf (34.9\%), and ramie (34.8\%).

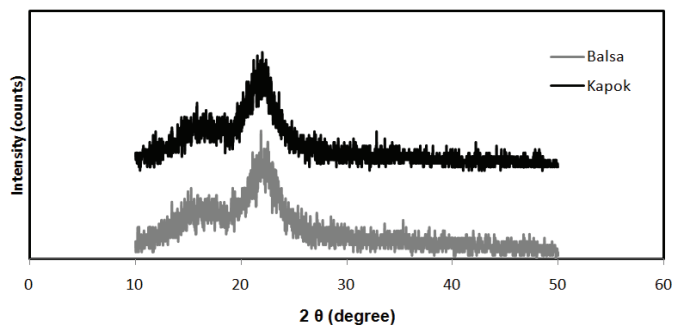

Fig. 3. X-ray diffractograms of kapok (black) and balsa (gray) fibers. 
Table 2. Crystalline characteristics of kapok and balsa fibers

\begin{tabular}{lcc}
\hline Variable & Kapok & Balsa \\
\hline \hline Relative crystallinity (\%) & 35.65 & 31.40 \\
Crystallite width (nm) & 4.70 & 3.70 \\
\hline
\end{tabular}

Table 2 presents the crystallinity index (\%) and the crystallite width for kapok and balsa fibers. The crystal widths of both fibers were larger than those of kenaf (Lee et al., 2008) and wood cellulose (Eun et al., 2008).

\subsection{Wettability}

The contact angles for the three types of liquid tested (water, methanol, and hexane) on kapok and balsa fibers after 0,5 , and $10 \mathrm{~min}$ following the droplet deposition are presented in Table 3 .

The study of wettability uses contact angle measurements which simulate the degree of wetting during the interaction between solids and liquids. A small contact angle $\left(<90^{\circ}\right)$ refers to high wettability, whereas a large contact angle $\left(>90^{\circ}\right)$ refers to a low wettability.

Table 3 shows that the contact angle of water with kapok fiber was higher than that with balsa fiber. This phenomenon indicated a lower wettability for kapok fiber than that for balsa fiber. The larger the contact angle, the longer the liquid would stay above the fiber surface (i.e., low wettability). The other two test liquids, methanol and hexane, formed very small contact angles
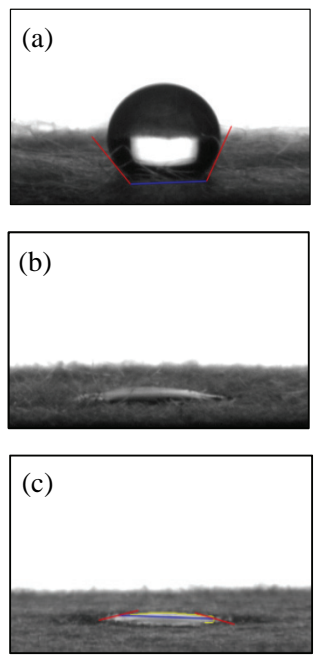

Kapok

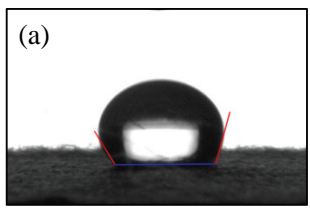

(b)

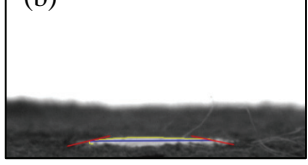

(c)

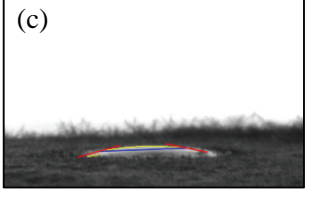

Balsa
Fig. 4. Contact angle for kapok and balsa fibers with three test liquids: (a) water, (b) methanol, and (c) hexane.

(Fig. 4) and exhibited much lower surface energies than water.

Contact angle is the angle between the fiber surface and the tangent to the drop profile at the drop edge (Njobuenwu et al., 2007). A large contact angle with water illustrates a hydrophobic and non-polar fiber surface. Hydrophobic properties are associated with the wax content of the fiber surface. Schellbach et al. (2015) stated that the wetting characterization of natural fibers through contact angle measurement aims to predict the compatibility and interaction between fiber and

Table 3. Contact angles of liquids tested on the fiber surface

\begin{tabular}{lcccc}
\hline \multirow{2}{*}{ Fiber type } & Time $(\min )$ & \multicolumn{3}{c}{ Contact angle $\left(^{\circ}\right)$} \\
\cline { 3 - 5 } & 0 & $120.74 \pm 1.45$ & Methanol & Hexane \\
\hline \hline Kapok & 5 & $117.24 \pm 0.32$ & $12.33 \pm 0.30$ & $12.67 \pm 0.35$ \\
& 10 & $113.12 \pm 0.20$ & 0 & 0 \\
\hline Balsa & 0 & $109.98 \pm 1.51$ & $11.81 \pm 0.08$ & 0 \\
& 5 & $104.46 \pm 1.58$ & 0 & 0 \\
& 10 & $102.82 \pm 0.13$ & 0 & 0 \\
\hline
\end{tabular}


Renny Purnawati $\cdot$ Fauzi Febrianto $\cdot$ I Nyoman $\mathrm{J}$ Wistara $\cdot$ Siti Nikmatin $\cdot$ Wahyu Hidayat

Seung Hwan Lee $\cdot$ Nam Hun Kim

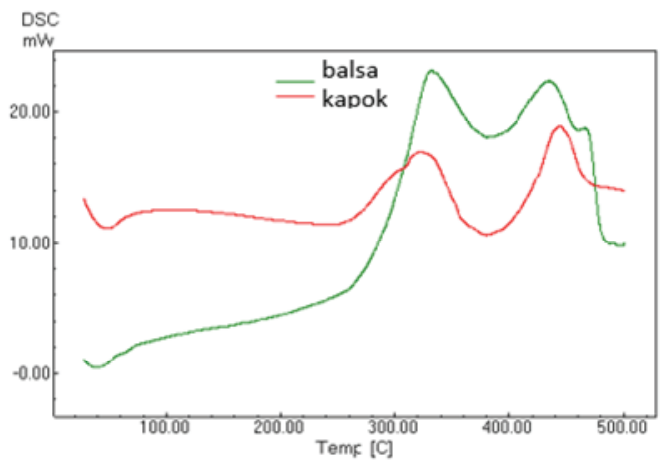

Fig. 5. DSC curves of kapok (red) and balsa (green).

polymers that have various surface energies.

\subsection{Analysis of thermal properties}

The DSC technique can be used to determine a drop in crystallinity and decomposition of plant fiber cellulose (Mwaikambo and Ansell 2002). There are three types of weight/mass loss during thermal degradation: water removal (drying), organic matter release (devolatilization), and bonded-carbon oxidation (slow combustion). From the DSC results, kapok and balsa fibers were shown to follow a similar fiber degradation process (Fig. 5).

The first peak is endothermic, and it indicated water desorption, as seen in the temperature range of 29.9 ${ }^{\circ} \mathrm{C}-65.1{ }^{\circ} \mathrm{C}$ for kapok fiber and $29.9{ }^{\circ} \mathrm{C}-57.0{ }^{\circ} \mathrm{C}$ for balsa fiber. The second and third peaks are exothermic, and they occurred at $322.8^{\circ} \mathrm{C}$ and 444.1 ${ }^{\circ} \mathrm{C}$ for kapok fiber and at $333.2{ }^{\circ} \mathrm{C}$ and $434.7^{\circ} \mathrm{C}$ for balsa fiber. The second peak was expected to represent the degradation of the hemicellulose, as well as the amorphous part of cellulose. According to Jin et al. (2010), hemicellulosic depolymerization might occur at a temperature of $180{ }^{\circ} \mathrm{C}-340{ }^{\circ} \mathrm{C}$, and breakage of the cellulosic glycosidic bond might occur at $275{ }^{\circ} \mathrm{C}$ - $350{ }^{\circ} \mathrm{C}$ (Poletto et al., 2012).

The third peak expressed the final decomposition of cellulose, as well as lignin degradation. Gaan et al. (2009) identified three stages of cellulose thermal decomposition. The first stage occurred at a temperature of $100{ }^{\circ} \mathrm{C}$ and represented the release of water. The second stage, at a temperature of $360{ }^{\circ} \mathrm{C}$, was a rapid dehydration and decarboxylation reaction that produced combustible gases such as aldehydes, ketones, and ethers. The third stage, at $400{ }^{\circ} \mathrm{C}$, was classified as the second stage of decomposition and charcoal formation. Lignin degradation occurred at a temperature of $250{ }^{\circ} \mathrm{C}-500{ }^{\circ} \mathrm{C}$ because of its high stability, which made it difficult to decompose (Poletto et al., 2012).

\subsection{Chemical components}

The solubility of balsa fiber in hot and cold water was higher than that of kapok fiber, and its content of $\alpha$-cellulose, lignin, and silica was also higher than that of kapok fiber (Table 4). In contrast, the solubility in $1 \% \mathrm{NaOH}$ and the content of ash and wax were higher for balsa than for kapok. Compared with cotton fiber, kapok fiber had a lower cellulose content and a higher lignin content (Mani et al., 2012). Cotton contained a significant amount of cellulose, ranging

Table 4. Chemical components of kapok and balsa fibers

\begin{tabular}{lcr}
\hline $\begin{array}{c}\text { Chemical } \\
\text { component (\%) }\end{array}$ & Kapok & \multicolumn{1}{c}{ Balsa } \\
\hline \hline Moisture content & $11.23 \pm 0.08$ & $11.45 \pm 0.16$ \\
Solubility & & \\
$\quad$ a. Cold water & $2.70 \pm 0.38$ & $3.21 \pm 0.07$ \\
$\quad$ b. Hot water & $4.42 \pm 0.12$ & $6.04 \pm 2.42$ \\
$\quad$ c. NaOH 1\% & $30.20 \pm 0.72$ & $26.02 \pm 0.92$ \\
Holocellulose & $83.73 \pm 0.49$ & $81.97 \pm 0.63$ \\
a-cellulose & $38.09 \pm 0.61$ & $44.62 \pm 1.05$ \\
Lignin & $14.10 \pm 0.84$ & $16.60 \pm 0.49$ \\
Ash & $1.05 \pm 0.04$ & $0.94 \pm 0.03$ \\
Silica & $0.45 \pm 0.03$ & $0.49 \pm 0.13$ \\
Wax content & $2.34 \pm 0.06$ & $2.29 \pm 0.11$ \\
\hline
\end{tabular}




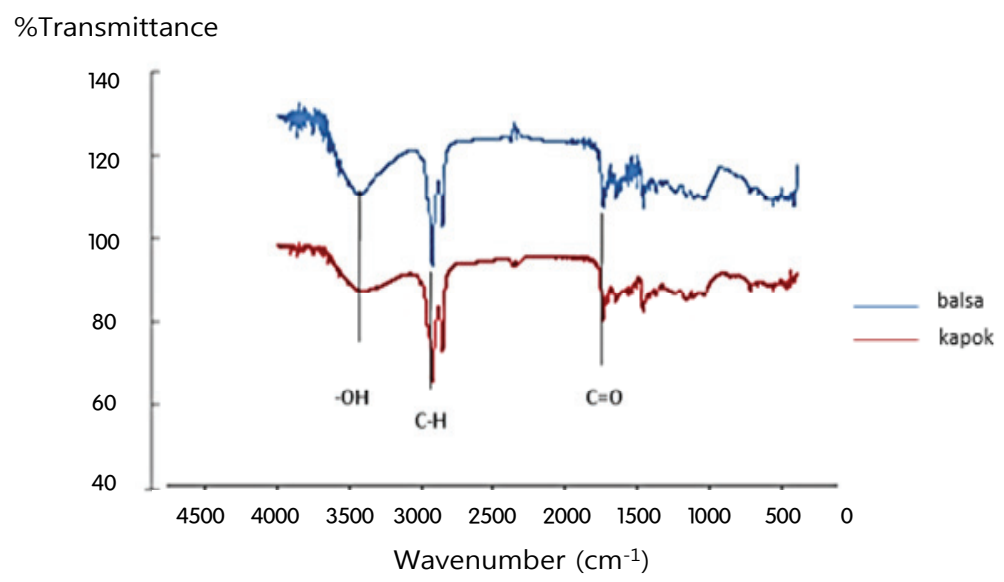

Fig. 6. FTIR spectra of kapok (red) and balsa (blue) fibers.

from $82 \%$ to $96 \%$, with a lignin content of $0 \%-5 \%$ (Mwaikambo, 2006).

Previous studies on the chemical components of kapok stated that its fiber contained a large amount of organic lignin at $15 \%-22 \%, 35 \%-50 \%$ of cellulose, $22 \%-45 \%$ of hemicellulose, and $2 \%-3 \%$ of wax. It also contained small amounts of starch, approximately $2.1 \%$ of protein, and some inorganic substances, notably iron content of $1.3 \%-2.5 \%$ (Smole et al., 2013). Considering the content of $\alpha$-cellulose, kapok was more similar to wood than flax and other plant fibers (Fengel, 1986).

\subsection{Functional group characterization}

The FTIR spectra of kapok and balsa fibers are shown in Fig. 6. There were similar absorption bands for both fibers. An -OH functional group appeared at a wavenumber of $3356 \mathrm{~cm}^{-1}$ for kapok fiber and at 3425 $\mathrm{cm}^{-1}$ for balsa fiber, and C-H stretching was found at a wavenumber of $2916 \mathrm{~cm}^{-1}$ for kapok fiber and at $2908 \mathrm{~cm}^{-1}$ for balsa fiber. Both functional groups of $-\mathrm{OH}$ and $\mathrm{C}-\mathrm{H}$ at these wavenumbers indicated the presence of cellulose, hemicellulose, and lignin (Moran et al. 2008). Meanwhile, the carbonyl group $(\mathrm{C}=\mathrm{O})$ found at $1736 \mathrm{~cm}^{-1}$ indicated the presence of hemicellulose (Chandrabakty, 2014).

The absorption peak at $1250 \mathrm{~cm}^{-1}$ for both fibers was associated with stretching of the aryl-alkyl ether group in lignin (Nazir et al., 2013). Meanwhile, the characteristic band located at $1034 \mathrm{~cm}^{-1}$ for balsa fiber and $1049 \mathrm{~cm}^{-1}$ for kapok fiber indicated the vibration of C-O-C or C-O in cellulose (Solikhin et al., 2016).

\section{CONCLUSION}

Kapok and balsa fibers had hollow structures with thin fiber walls and large lumen; therefore, they could potentially be developed as absorbent and insulating materials. There were similarities in terms of structure and properties between kapok and balsa fibers derived from seedpods. Kapok and balsa fibers were significantly hydrophobic because of the wax content found on the surfaces of both fibers. The chemical compositions of natural fibers, represented by the percentage of cellulose, hemicellulose, lignin, and wax, also contributed largely to the characteristics of the products. The main chemical components of kapok and balsa were cellulose, hemicellulose, and lignin as supported by FTIR, XRD, and DSC analyses. 
Renny Purnawati $\cdot$ Fauzi Febrianto $\cdot$ I Nyoman $\mathrm{J}$ Wistara $\cdot$ Siti Nikmatin $\cdot$ Wahyu Hidayat

Seung Hwan Lee $\cdot$ Nam Hun Kim

\section{ACKNOWLEDGMENT}

Authors acknowledge the support from the Ministry of Research, Technology and Higher Education of the Republic of Indonesia for funding this research through the International Research Collaboration and Scientific Publication scheme in 2017.

\section{REFERENCES}

American Association of Textile Chemists and Colorists. 2012. AATCC Test Method 97. Extractable content of textiles. United States: AATCC Technical Manual.

Browning, B.L. 1967. Methods of Wood Chemistry. Volume 2. New York: Interscience Publishing.

Central Bureau of Statistics Republic of Indonesia (BPS). 2015. Area and production of community forest plantation by species (2000-2015). Jakarta (ID): Central Bureau of Statistics

Chandrabakty, S. 2014. Fourier transform infrared (FT-IR) spectroscopy and tensile strength of melinjo's stem bark using modification of Weibull distribution. Jurnal Mekanikal (5): 434-442.

Eun, D.J., Kwon, S.M., Kim, N.H. 2008. Variation of fine structure of wood cellulose within stems of 3 commercial softwoods species grown in Korea. Journal of the Korean Wood Science and Technology 36(1): 12-20.

Fengel, D., Przyklenk, M. 1986. Studies on kapok 2. Chemical Investigation. Holzforschung 40: 325330.

Gaan, S., Rupper, P., Salimova, V. 2009. Thermal decomposition and burning behavior of cellulose treated with ethyl ester phosphoramides: effect of alkyl substituent on nitrogen atom. Polymer Degradation and Stability 4(7): 1025-1134.

Jin, LG., Wu, S.B., Lou, R. 2010. Kinetic study of the thermal decomposition of hemicellulose isolated from corn stalk. Bioresources 5(2): 1281-1291.

Lee, S.H, Kwon, S.M., Um, G.J., Kim, N.H. 2008. Anatomical characteristics of kenaf grown in reclaimed land. Journal of the Korean Wood Science and Technology 36(4): 11-18.

Likon, M., Remskar, M., Ducman, V., Svegl, F. 2013. Populus seed fibers as a natural source for production of oil super absorbents. Journal Environmental Management. 114:158-167.

Lim, T.T., Huang, X. 2007. Evaluation of kapok (Ceiba pentandra (L.) Gaertn.) as a natural hollow hydrophobic-oleophilic fibrous sorbent for oil spill cleanup. Chemosphere 66: 955-963.

Mani, G.K., Rayappan, J.B.B., Bisoyi, D.K. 2012. Synthesis and characterization of kapok fiber and its composites. Journal of Applied Science 12: 1661 $-1665$.

Meiwu, S., Hong, X., Weidong, Y. 2010. The fine structure of the kapok fiber. Textile Research Journal 80(2): 159-165.

Moran, J.I., Alvarez, V.A., Cyras, V.P., Vazquez, A. 2008. Extraction of cellulose and preparation of nanocellulose from sisal fibers. Cellulose (15): 149159.

Mwaikambo, L.Y. 2006. Review of the history, properties, and application of plant fibres. African Journal of Science and Technology 7: 120-133.

Mwaikambo, L.Y., Ansell, M.P. 2002. Chemical modification of hemp, sisal, jute, and kapok fibers by alkalization. Journal of Applied Polymer Science 84: 2222-2234.

Nazir, M.S., Wahjoedi, B.A., Yussof, A.W., Abdullah, M.A. 2013. Eco-Friendly Extraction and Characterization of Cellulose from Oil Palm Empty Fruit Bunches. Bioresources 8(2): 2161-2172.

Njobuenwu, D.O., Oboho, E.O., Gumus, R.H. 2007. Determination of contact angle from contact area of liquid droplet spreading on solid substrate. Leonardo Electronic Journal of Practices and 
Technologies 6(10): 29-38.

Poletto, M., Zattera, A.J., Forte, M., Santana, R. 2012. Thermal decomposition of wood: influence of wood components and cellulose crystallite size. Bioresource Technology 109: 148-153.

Poletto, M., Ornaghi, H.L., Zattera, A.J. 2014. Native cellulose: structure, characterization, and thermal properties. Materials 7: 6105-6119.

Purnawati, R., Febrianto, F., Wistara, N.J., Nikmatin, S., Sudirman, Marwanto, Kim, N.H. 2018. Alkaline treated-kapok and balsa fibers for composite reinforcement. JITKT 16(1): 21-31.

Reddy, N., Yang, Y. 2004. Biofibers from agricultural byproducts for industrial applications. Trends in Biotechnology 23: 22-27.

Rengasamy, R.S., Das, D., Karan, C.P. 2011. Study of oil sorption behavior of filled and structured fiber assemblies made from polypropylene, kapok, and milkweed fibers. Journal of Hazardous Materials 186: 526-532.

Schellbach, S.L., Monteiro, S.N., Drelich, J.W. 2015. A novel method for contact angle measurements on natural fibers. Material Letters 164: 599-604.

Segal, L., Creely, J.J., Martin, A.E., Conrad, C.M. 1959. An empirical method for estimating the degree of crystallinity of native cellulose using X-ray diffractometer. Textile Research Journal 29(10): 786-794.

Smilgies, D.M. 2009. Scherrer grain-size analysis adapted to grazing-incidence scattering with area detectors. Journal Applied Crystallography 42(6): 1030-1034.

Smole, M.S., Hribernik, S., Kleinschek, K.S., Kreže, T. 2013. Plant Fibers for Textile and Technical
Applications. Chapter 15. InTech Open. http://dx.doi.org/10.57772/52372

Solikhin, A., Hadi, Y.S., Massijaya, M.Y., Nikmatin, S. 2016. Basic properties of oven-heat treated oil palm empty fruit bunch stalk fibers. Bioresources 11(1): 2224-2237.

Suryadi, G.S. 2017. Studies of microstructure, thermal, mechanics, and surface properties of oil palm empty fruit bunches reinforced biocomposites. Thesis. Graduate School of Bogor Agricultural University (IPB), Bogor Indonesia.

Technical Association of the Pulp and Paper Industry. 1988. TAPPI T204 om-88. Solvent extractives of wood and pulp. Atlanta: TAPPI Press.

Technical Association of the Pulp and Paper Industry. 2002. TAPPI T211 om-02. Ash in wood, pulp, paper, and paperboard: combustion at $525{ }^{\circ} \mathrm{C}$. Atlanta: TAPPI Press.

Technical Association of the Pulp and Paper Industry. 1988. TAPPI T222 om-88. Acid-insoluble lignin in wood and pulp. Atlanta: TAPPI Press.

Veerakumar, A., Selvakumar, N. 2012. A preliminary investigation on kapok/polypropylene nonwoven composite for sound absorption. Indian Journal of Fibre and Textile Research (37): 385-388.

Wang, J., Zheng, Y., Wang, A. 2012. Super hydrophobic kapok fiber oil-absorbent: preparation and high oil absorbency. Chemical Engineering Journal 213: 17.

Zheng, Y., Wang, J., Zhu, Y., Wang, A. 2015. Research and application of kapok fiber as an absorbing material: A mini review. Journal of Environmental Science 27: 21-32. 